\title{
Chemical Screening, Antioxidant Potential and Antiangiogenic Effect of Microporus Xanthopus (fr.) Kuntze, Ganoderma Orbiforme (fr.) Ryvarden and Polyporus Fasciculatus (pat) lloyd, Medicinal Mushrooms from Gabon
}

\author{
Orango-Bourdette Juliette-Ornely ${ }^{1,2}$, Eyi-Ndong Hugues Calixte ${ }^{3}$, Ndong-Atome Guy \\ Roger $^{1,2}$, Ngoua Meye Misso Rick-Léonid ${ }^{1,2}$, Sima-Obiang Cédric ${ }^{1,2}$, Ondo Joseph- \\ Privat $^{1,2}$, Obame-Engonga Louis-Clément ${ }^{1,2^{*}}$ \\ 1. Laboratory of Research in Biochemistry (LAREBIO), University of Sciences and \\ Technology of Masuku, Franceville, Gabon. \\ 2. Laboratory of Natural Substances and Organometallic Synthesis (LASNSOM), \\ University of Sciences and Technology of Masuku, Franceville, Gabon. \\ 3. Institute of Technological Research (IRT), CENAREST-Libreville, Gabon.
}

\begin{abstract}
The objective of the present study was investigation of the chemical screening, antioxidant potential and antiangiogenic effect of Microporus xanthopus, Ganoderma orbiforme and Polyporus fasciculatus, medicinal mushrooms from Gabon. Theantioxidant activities of water, water-ethanol and ethanol extracts of three fungi were tested by measuring the trapping power of DPPH radical. The anti-angiogenic activity was evaluated for some water extracts by chicken chorioallantoic membrane method (CAM). The results obtained for DPPH trapping test showed that the various extracts tested had antioxidant activities going from low to very high. The greatest activities were found in Microporus xanthopus with IAAs of 3.88 and 4.13, respectively, for water and water-ethanol extracts. Polyporus fasciculatus fungi exhibited strong antioxidant activities. The moderate activity was found in the extract of Ganoderma orbiforme. The water extracts tested for their anti-angiogenic activity acted by decreasing the density and/or number of blood vessels of the CAM with inhibition percentages of $66.67 \%$, $55.45 \%$ and $37 \%$, for Ganoderma orbiforme, Microporus xanthopus and Polyporus fasciculatus, respectively. Thus, angiogenesis can be neutralized by the antioxidant molecules contained in the fungi, but these molecules are not the only ones to possess these potentialities. Harvested mushrooms could be potential agents for the fight against cancer.
\end{abstract}

Keywords: Cancer, antioxidant and anti-angiogenic activities, phenolic compounds, CAM, mushrooms.

*Corresponding Author Email obamengonga2@gmail.com

Received 10 September 2018, Accepted 02 October 2018

Please cite this article as: Obame-Engonga . et al., Chemical Screening, Antioxidant Potential and Antiangiogenic Effect of Microporus Xanthopus (fr.) Kuntze, Ganoderma Orbiforme (fr.) Ryvarden and Polyporus Fasciculatus (pat) lloyd, Medicinal Mushrooms from Gabon. American Journal of Pharmacy \& Health Research 2018. 


\section{INTRODUCTION}

The cell is the basic functional and structural unit of living organisms. It contains genetic information and various biological elements that allow it to be autonomous, viable and able to multiply. Cell multiplication is a finely regulated process. Indeed, the mechanisms of cell growth are usually clear and the cells obey. However, in certain situations, following a set of mutations, some cells escape this regulation and turn into cancer cells. Cancer is one of the leading causes of morbidity and mortality worldwide [1]. In 2012, there were approximately 14 million new cases and 8.2 million global deaths related to the disease [2]. In Gabon, there were 110,000 new cases in 2008 [3]. It is estimated that the number of cancers per year is expected to increase by $70 \%$ over the next two decades [4]. As a result, the fight against cancer represents a major public health challenge. Despite the multiple faces of this disease, the research work of the last thirty years made it possible to define points common to the various cancers. Cancer cells differ from normal cells by several criteria, including an overproduction of free radicals (ROS), which is responsible for the activation of tumor angiogenesis. Angiogenesis is the biological process by which new vessels are formed from preexisting vessels. Its involvement in tumor growth was first stated by Folkmanin 1971. The hypothesis of the latter states that tumor growth depends on angiogenesis and that inhibition of angiogenesis could have therapeutic effects [5]. Similarly, in the last two decades, reactive oxygen species (ROS) have been presented in many studies as a key component of carcinogenesis. Indeed, they would intervene in all stages of carcinogenesis including transformation, promotion, progression, angiogenesis and tumor metastases [6,7]. Their effects can be neutralized or prevented by molecules called antioxidants. Antioxidants of natural origin mainly belong to the group of phenolic compounds. These are found in all natural substances like mushrooms. Used for millennia in traditional Japanese and Chinese medicine, mushrooms are presented as living beings with nutritional values and a large number of therapeutic properties. A total of 126 medicinal properties are attributed to them, including antioxidant, anti-cancer, antitumor, antiviral, antibacterial, immunomodulatory, hepatoprotective and antidiabetic effects [8]. However, in Africa, especially in Gabon, mushrooms are only known for their food use and toxicity. Their therapeutic potential is known only by a minority of peoples. Thus, because of the importance of ROS and angiogenesis in carcinogenesis, in this work, the antioxidant and anti-angiogenic potentialities of three (3) fungi of Gabon were tested, from a perspective of research of new molecules. 


\section{MATERIALS AND METHOD}

\section{Fungal material}

Microporus xanthopus, Ganoderma orbiforme and Polyporus fasciculatus were harvested at Monda and Malibé II forest in August 2016. The specimens were authenticated by Dr. Eyi Ndong Hugues (Biochemist-Mycologist) and deposited at Institute of Technological Research (IRT) CENAREST-Libreville and at Biochemistry Research Laboratory (LAREBIO), Faculty of Science, USTM-Franceville. The collected mushrooms were described macroscopically, then the identification of the collections was made by a microscopic study (Olympus CX31 with sampling tube) of the dry matter, with as a means of observation of the red Congo in ammonia or the solution of Melzer [9]. The reference works used are essentially "Illustrated flora of mushrooms from Central Africa", "Iconographic flora of Congo mushrooms", "Fungus Flora from tropical Africa", especially for the genera Volvariella, Cantharellus, Lentinus, for edible mushrooms from dense Central African forests taxonomy and identification and guide to edible fungi of Benin.

\section{Preparation of fungal extract}

Water-ethanol $(50 / 50 \mathrm{v} / \mathrm{v})$, ethanol and water extractswere prepared from dry powder. $50 \mathrm{~g}$ of powder from each sample were soaked with $500 \mathrm{~mL}$ of the appropriate solvent mixture and left under shaking conditions at room temperature $\left(25^{\circ} \mathrm{C}\right)$ for $24 \mathrm{~h}$. Water extract was prepared by maceration mixing $50 \mathrm{~g}$ of powder to $500 \mathrm{~mL}$ of distilled water. The mixture was boiled for 72 h. Each extract was filtered using Whatman $\mathrm{N}^{\circ} 1$ filter paper and solvents were completely removed at low pressure with a rotary evaporator (Büchi, Labortechnik, Switzerland). The extracts were then concentrated, freeze-dried and stored at $4^{\circ} \mathrm{C}$ until analysis.

\section{Chemical screening}

Each extract was then tested for the presence of flavonoids, coumarins, tannins, total phenolic, saponosids, cardiac glycosides, reducing sugar, sterols and triterpenes, oses and holosides, anthracenics, anthocyans, alkaloids and anthracenosids as described elsewhere [10].

\section{Total Phenolic Content}

The total phenolic contents of the different extracts were determined according to the FolinCiocalteu Method [11] with minor modifications as described by Sima et al. [12] using gallic acid as standard. The absorbance was measured at $735 \mathrm{~nm}$ using a multiwell plate reader ( $\mu$ Quant Bio-Tek Instrument, Inc, USA). All analyses were done in triplicate and results (average of triplicate analysis) were expressed as gallic acid equivalent per gram of lyophilized sample.

\section{Total Flavonoid Content}

Total flavonoid contents were determined by the aluminum chloride $\left(\mathrm{AlCl}_{3}\right)$ colorimetric assay 
method [13] adapted to 96 well-plate, using quercetin as a standard [14]. The total flavonoid contents were expressed as quercetin equivalents in milligrams per gram sample (average of the triplicate analysis).

\section{Tannins content}

The reference method of European community was used to measure total amount of tannins (1994) [15]. Tannic acid was used like standard.

\section{Proanthocyanidins (PAs) content}

The method consists on the hydrolysis of proanthocyanidins in a hot acid-alcohol medium into anthocyanidins. This method allows taking into account all the units of flavans-3-ols constituting the polymers [16]. The assay is performed by mixing $50 \mu \mathrm{L}$ of the extract with 700 $\mu \mathrm{L}$ of $30 \% \mathrm{HCl}$-butanol solution (v/v). The mixture was put in tightly closed $1.5 \mathrm{~mL}$ Eppendorf tube and vortexed for $1 \mathrm{~min}$. Subsequently, the tube was heated at $100^{\circ} \mathrm{C}$ for $2 \mathrm{~h}$ and after cooling, $200 \mu \mathrm{L}$ aliquots were put in triplicate into a 96-well plate and the absorbance were read at $550 \mathrm{~nm}$. Apple procyanidins $(\mathrm{DP} \approx 7.4)$ treated as aforementioned were used as a standard. Results were expressed as apple procyanidins equivalent (APE).

\section{Antioxidant Activity Index}

The Antioxidant Activity Index (AAI) was assessed according to the method described by Scherer and Godoy in 2009 [17]. This method is based on the DPPH radical test. Briefly, the working reagent was prepared by dissolving $10 \mathrm{mg}$ of DPPH in $100 \mathrm{~mL}$ ethanol. Graded concentrations of extracts ranging from 0.781 to $100 \mu \mathrm{g} / \mathrm{mL}$ obtained by two-fold dilutions were prepared and $100 \mu \mathrm{L}$ of each dilution were mixed with $100 \mu \mathrm{L}$ of the working solution of DPPH in a 96-well plate. Absorbencies were measured at $517 \mathrm{~nm}$ after 15 min incubation at room temperature in the dark. Ascorbic acid (Vitamin C) and Butylated Hydroxyanisole (BHA) were used as references. The ability to scavenge DPPH radical was calculated by the following equation: \% RSA $=[($ A control $-\mathrm{A}$ sample $) / \mathrm{A}$ control $] \times 100$.

$\mathrm{A}=$ Absorbance at $517 \mathrm{~nm}$.

The $\mathrm{IC}_{50}$ (concentration providing $50 \%$ inhibition) of extracts and standards was determinate using regression curves in the linear range of concentrations. The AAI was then calculated as follows: $\mathrm{AAI}=[\mathrm{DPPH}](\mu \mathrm{g} / \mathrm{mL}) / \mathrm{IC}_{50}(\mu \mathrm{g} / \mathrm{mL})$.

$[\mathrm{DPPH}]$ is the final concentration of DPPH. We considered criteria of Scherer and Godoy (2009) according to which plant extracts show poor antioxidant activity when AAI $<0.5$, moderate antioxidant activity when AAI is between 0.5 and 1.0 , strong antioxidant activity when $\mathrm{AAI}$ is between 1.0 and 2.0, and very strong when $\mathrm{AAI}>2.0$.

\section{Evaluation of Antiangiogenic Activity}

Chick Chorioallantoic Membrane Model (CAM): In this assay, the antiangiogenic efficacy of 
water extracts of Microporus xanthopus, Ganoderma orbiforme and Polyporus fasciculatus, was evaluated according to previously reported methods $[18,19]$. Fertilized chicken eggs were purchased from a local poultry farm, were sterilized with $70^{\circ}$ ethanol and incubated at $37^{\circ} \mathrm{C}$ in an egg incubator (Lab. Incubator, Digisystem Laboratory Instruments inc.), with 60-65\% relative humidity. On day 3 of post incubation, 2 to $3 \mathrm{~mL}$ of albumin were withdrawn, using a 21 gauge needle, through a small opening at the large blunt edge of the egg to minimize adhesion of the shell membrane with CAM. A square window of $1 \mathrm{~cm}^{2}$ was opened in the egg shell at the opposite to blunt edge and sealed with an adhesive tape to prevent dehydration. Then the adhesive tape is replaced after every 24 hours in order to remove water drops deposited. The eggs were returned for further incubation. At the $8^{\text {th }}$ day, the experimental groups were divided into 3 of each containing 30 numbers of eggs. Group 1 and 2 were treated with water extracts. Sterile discs (diameter: $10 \mathrm{~mm}$ ) of Whatman $\mathrm{N}^{\circ} 1$ soaked of $10 \mu \mathrm{L}$ of the water extract at concentrations ranging from 0.25 to $0.50 \mathrm{mg} / \mathrm{mL}$ was applied to the CAM. In parallel Group 3 treated with phosphate buffered saline (PBS) alone as control, a paper disc Whatman $\mathrm{N}^{\circ} 1$ soaked of $10 \mu \mathrm{L}$ PBS at $\mathrm{pH} 7$ was placed on the CAM of egg. On the $9^{\text {th }}$ day, a volume of $10 \mu \mathrm{L}$ of para-formaldehyde was applied to the CAM. 10 min later, the CAM was cut around the disk using a small pair of sharp scissors and all disc (CAM) was placed in a Petri dish containing agarose gel $1.6 \%$. Then the photos were taken with a cannon digital camera of $16 \times 5.0$ Mega Pixel (made in China) and the images were subsequently analyzed with the software Image J. The percentage of vascularization (density) is measured relative to a normal control vascularization.

\section{Statistical Analysis}

The data were expressed as the mean \pm standard deviation (SD) of three independent experiments and analyzed using one-way analysis of variance and Student's t-test. p-values of $<0.05$ were considered to be statistically significant.

\section{RESULTS AND DISCUSSION}

\section{Results}

The three medicinal mushrooms studied Microporus xanthopus, Ganoderma orbiforme and Polyporus fasciculatus are represented in figure 1. 


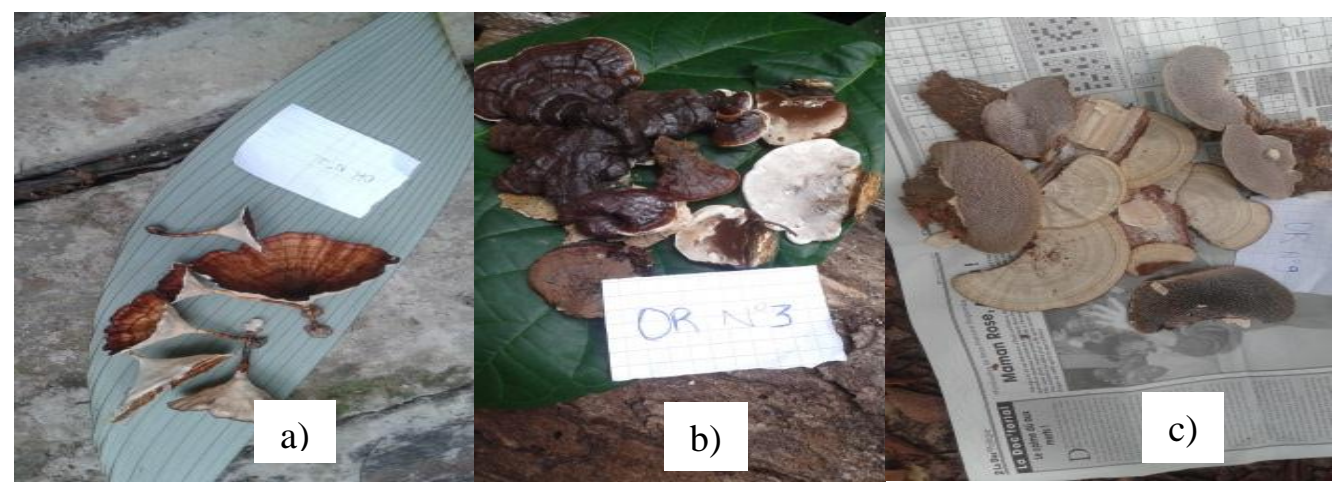

Figure 1: Identification of fungi

a) Microporus xanthopus, b) Ganoderma orbiforme, c) Polyporus fasciculatus,

Selecting the proper extraction method is a very important parameter for obtaining extracts with acceptable yields. The selection of a proper solvent may affect the quantity and quality of the resulting extracts. Various organic compounds including phenolics and flavonoids have solubility in ethanol and water.

\section{Chemical screening}

The phytochemical screening of the extracts was first performed to detect the major chemical groups occurring in the extracts. In view of the results in table 1, 
Table 1: Chemical groups detected in Microporus xanthopus, Ganoderma orbiforme and Polyporus fasciculatus fungal extracts

\begin{tabular}{|c|c|c|c|c|c|c|c|c|c|c|}
\hline \multirow{2}{*}{\multicolumn{2}{|c|}{ Chemical Groups }} & \multicolumn{3}{|c|}{ Microporus xanthopus } & \multicolumn{3}{|c|}{ Ganoderma orbiforme } & \multicolumn{3}{|c|}{ Polyporus fasciculatus } \\
\hline & & Aq & Eth-Aq & Eth & $\mathbf{A q}$ & Eth-Aq & Eth & $\mathbf{A q}$ & Eth-Aq & Eth \\
\hline \multicolumn{2}{|l|}{ Saponosids } & ++ & - & - & +++ & - & - & ++ & - & - \\
\hline \multicolumn{2}{|l|}{ Polyphenols } & +++ & +++ & +++ & +++ & +++ & +++ & +++ & +++ & +++ \\
\hline \multicolumn{2}{|c|}{ Sterols and triterpenes } & - & - & - & ++ & ++ & ++ & - & - & - \\
\hline \multicolumn{2}{|l|}{ Oses and holosides } & - & - & - & - & +++ & +++ & - & - & - \\
\hline & Gallics & - & + & + & + & ++ & ++ & +++ & +++ & ++ \\
\hline Tannins & Catechics & - & - & - & - & - & - & ++ & +++ & +++ \\
\hline \multirow[t]{2}{*}{ Alkaloids } & & ++ & ++ & ++ & +++ & ++ & ++ & +++ & +++ & +++ \\
\hline & Flavons & - & - & - & - & - & +++ & ++ & +++ & ++ \\
\hline \multirow[t]{3}{*}{ Cyanidins } & Flavanons & + & +++ & ++ & +++ & +++ & +++ & - & - & - \\
\hline & Flavonols & - & - & - & - & - & - & - & - & - \\
\hline & Flavanonols & - & - & - & - & - & - & - & - & - \\
\hline Total flavonoids & & + & +++ & + & ++ & +++ & +++ & ++ & +++ & + \\
\hline Anthocyans & & - & + & - & ++ & ++ & +++ & ++ & +++ & ++ \\
\hline Proanthocyanidins & & + & +++ & - & ++ & ++ & +++ & + & +++ & ++ \\
\hline Anthracenics & & + & ++ & + & +++ & +++ & +++ & ++ & +++ & ++ \\
\hline \multirow[t]{2}{*}{ Coumarins } & & ++ & ++ & ++ & +++ & ++ & ++ & +++ & +++ & +++ \\
\hline & Digitoxine & - & - & - & - & - & - & - & - & - \\
\hline \multirow{3}{*}{ Cardiac glycosides } & Digitoxigenine & - & - & - & - & - & - & - & - & - \\
\hline & Gitoxine & - & - & - & - & - & - & - & - & - \\
\hline & Gitoxigenine & ++ & +++ & - & - & - & - & ++ & +++ & ++ \\
\hline Reducingsugar & & - & - & - & +++ & +++ & +++ & ++ & +++ & ++ \\
\hline
\end{tabular}


it appears that three fungi studied Microporus xanthopus, Ganoderma orbiforme and Polyporus fasciculatus, contain abundant coumarins, polyphenols, alkaloids and reducing sugars. Chemical screening of Microporus xanthopus extracts show that all the extracts of this fungus are abundant in total polyphenols but moderately abundant in alkaloids, and in coumarins. Gitoxigenins, flavone, proanthocyanidines and total flavonoids are abundant in water-ethanol extract. Ganoderma orbiforme screening show that the extracts are all abundant in reducing sugars, total polyphenols, anthracenosidesand total flavonoids (flavones and flavones being abundant in the water and water-ethanol extracts). They are moderately abundant in sterols, triterpenes and gallic tannins. The aqueous extract is rich in digitoxins and saponosides; moderately abundant in proanthocyanidins. The water-ethanol extract is rich in oses, holosides and moderately abundant in digitoxins and anthracenosides. The ethanol extract is rich in oses, holosides and proanthocyanidins. Polyporus fasciculatus extracts are abundant in alkaloids, gallic tannins, total polyphenols and coumarins. Reducing sugar, flavone and gitoxigenins are moderately abundant in water and ethanol extracts but abundant in water-ethanol extract.

Total Phenolic, Total Flavonoid, Tannins and Proanthocyanidins contents

The contents of total phenolic, total flavonoids, total tannins and total proanthocyanidins of extracts from Microporus xanthopus, Ganoderma orbiforme and Polyporus fasciculatus, are presented in table 2.

Table 2. Total phenolic content (TPC), Total flavonoid content (TFC), Total Tannins Content (TTC) and Total Proanthocyanidins Content (TPC) of extracts from Microporus xanthopus, Ganoderma orbiforme and Polyporus fasciculatus.

\begin{tabular}{llllll}
\hline Extracts & & $\begin{array}{l}\text { Total phenolic } \\
\text { content (TPC) } \\
\text { (mgGAE/100 g } \\
\text { of drug) }\end{array}$ & $\begin{array}{l}\text { Total flavonoid } \\
\text { content (TFC) } \\
\text { (mgEQ/100 g of } \\
\text { drug) }\end{array}$ & $\begin{array}{l}\text { Total tannins } \\
\text { content (TTC) } \\
\text { (mgEAT/100 g of } \\
\text { drug) }\end{array}$ & $\begin{array}{l}\text { Total } \\
\text { proanthocyanidins } \\
\text { content (TPC) } \\
\text { (mgAPE/100 g ofdrug) }\end{array}$ \\
\hline Microporus & $\mathrm{Aq}$ & $5356.67 \pm 0$ & $160.37 \pm 7$ & 0 & $936.27 \pm 40$ \\
xanthopus & Eth-Aq & $34080 \pm 47$ & $4442.25 \pm 170$ & 0 & $64911.76 \pm 624$ \\
& Eth & $3882.50 \pm 348$ & $623.62 \pm 2$ & 0 & 0 \\
Ganoderma & Aq & $5496.33 \pm 78$ & $609.70 \pm 1$ & $18.09 \pm 2$ & $201.96 \pm 41$ \\
orbiforme & Eth-Aq & $7006.33 \pm 424$ & $2079.60 \pm 91$ & $1470.09 \pm 404$ & $500.98 \pm 62$ \\
& Eth & $5940.85 \pm 139$ & $301.57 \pm 0$ & $654.93 \pm 82$ & $431.01 \pm 13$ \\
Polyporus & Aq & $9168.57 \pm 620$ & $699.03 \pm 77$ & $581.08 \pm 188$ & $372.55 \pm 198$ \\
fasciculatus & Eth-Aq & $3870.26 \pm 69$ & $1425.75 \pm 0$ & $2272.20 \pm 74$ & $4797.13 \pm 474$ \\
& Eth & $3077.50 \pm 77$ & $212.25 \pm 5$ & $286 \pm 63$ & $139.70 \pm 98$ \\
\hline
\end{tabular}

$\mathrm{Aq}=$ Aqueous; Eth-Aq = Ethanol-aqueous; Eth = Ethanol.

The contents of total phenolic in terms of gallic acid equivalent (standard curve equation: $\mathrm{Y}=0.0012 \mathrm{X}-0.0004, \mathrm{R}^{2}=0.9902 ;$ [20] ranged from $3077.5 \pm 77$ to $9168.57 \pm 620 \mathrm{mg} \mathrm{GAE} / 100 \mathrm{~g}$ of drug. Total flavonoids (standard curve equation: $\mathrm{Y}=0.0032 \mathrm{X}+0.0077, \mathrm{R}^{2}=1$ ) ranged from $160.37 \pm 7$ to $4442.25 \pm 170 \mathrm{mg} \mathrm{EQ} / 100 \mathrm{~g}$ of drug. Levels of tannins were expressed in terms of 
tannic acid equivalent (TAE). The equation of the right-hand side of the proportioning of the total tannins by the reference method of European Community (1994) gave $\mathrm{Y}=0.0009 \mathrm{X}+0.2088$ with $\mathrm{R}^{2}=1$. Total tannins are ranged from $18.09 \pm 2$ to $2272.20 \pm 74 \mathrm{mg}$ $\mathrm{EQ} / 100 \mathrm{~g}$ of drug. There were abundant in water extracts than water-ethanol and ethanol extracts. Levels of proanthocyanidins were expressed in terms of apple proanthocyanidins equivalent (APE). The equation of the right-hand side of the proportioning of the proanthocyanidins by $\mathrm{HCl}-\mathrm{Butanol}$ method gave $\mathrm{Y}=0.0006 \mathrm{X}+0.0024$ with $\mathrm{R}^{2}=0.9869$ [20]. Among extracts, proanthocyanidin contents had ranged between $201.96 \pm 41$ to $64911.76 \pm 624$ mg APE/100 g of drug. The hydro-ethanolic extract of Microporus xanthopus has the highest levels of total polyphenols, total flavonoids and proanthocyanidin. The tannins are absent from the 3 extracts. The water extract has a higher phenolic content than ethanol extract. The results of the determination of Ganoderma orbiforme phenolic compounds show that the various extracts derived from this fungus are rich in polyphenol. All the same, their content is much higher in the water-ethanol extract. All extracts of Polyporus fasciculatus are abundant in total polyphenols. The aqueous extract is rich in gallic tannins and moderately abundant in catechin tannins. These results are inverses for ethanol extract. However, water-ethanol extract is rich in these two compounds.

\section{Antiradical activity}

The free radical-scavenging activities of various fungal extracts were evaluated at their initial concentration. All extracts show free radical scavenging activity (Table 3).

Table 3. Antioxidant Activity Index (AAI) of fungal extracts by DPPH free radical scavenging method.

\begin{tabular}{lllllll}
\hline Plants extracts & & Equations & $\mathbf{R}^{\mathbf{2}}$ & $\mathbf{I C}_{\mathbf{5 0}}(\boldsymbol{\mu} \mathbf{g} / \mathbf{m L})$ & AAI & Activity \\
\hline Microporus & $\mathrm{Aq}$ & $\mathrm{Y}=1602.6 \mathrm{X}+29.386$ & 0.9571 & 12.86 & 3.88 & Verystrong \\
xanthopus & Eth-Aq & $\mathrm{Y}=1679.9 \mathrm{X}+29.682$ & 0.9857 & 12.09 & 4.13 & Verystrong \\
& Eth & $\mathrm{Y}=273.34 \mathrm{X}+40.268$ & 0.9833 & 35.60 & 1.40 & Strong \\
Ganoderma & $\mathrm{Aq}$ & $\mathrm{Y}=165.23 \mathrm{X}+33.163$ & 0.9999 & 101.90 & 0.50 & Moderate \\
orbiforme & Eth-Aq & $\mathrm{Y}=224.26 \mathrm{X}+27.069$ & 0.9987 & 102.25 & 0.50 & Moderate \\
& Eth & $\mathrm{Y}=164.82 \mathrm{X}+25.784$ & 0.9912 & 146.92 & 0.34 & Poor \\
Polyporus & Aq & $\mathrm{Y}=289.27 \mathrm{X}+41.502$ & 0.996 & 29.38 & 1.70 & Strong \\
fasciculatus & Eth-Aq & $\mathrm{Y}=145.35 \mathrm{X}+46.021$ & 0.9974 & 27.37 & 1.83 & Strong \\
& Eth & $\mathrm{Y}=210.82 \mathrm{X}+35.200$ & 0.9114 & 70.20 & 0.71 & Moderate \\
Vitamin C & & $\mathrm{Y}=14.559 \mathrm{X}-0.613$ & 0.9990 & 3.48 & 11.32 & Verystrong \\
BHT & & $\mathrm{Y}=5.659 \mathrm{X}+11.513$ & 0.9960 & 6.30 & 7.85 & Verystrong \\
\hline
\end{tabular}

$\mathrm{Aq}=$ Aqueous $;$ Eth-Aq = Ethanol-aqueous $;$ Eth $=$ Ethanol, $\mathrm{BHT}=$ Butylated hydroxy toluene:

Positive control.

The crude extract of Microporus xanthopus, Ganoderma orbiforme and Polyporus fasciculatus show best DPPH free radical-scavenging activities ( IC $_{50}$ values ranged from 12.90 to 35.60 $\mu \mathrm{g} / \mathrm{mL}$ for Microporusxanthopus, 101.90 to $146.92 \mu \mathrm{g} / \mathrm{mL}$ for Ganoderma orbiforme and 27.37 
to $70.20 \mu \mathrm{g} / \mathrm{mL}$ for Polyporus fasciculatus. As it can be seen, AAI of extracts ranged from 0.34 to 4.13 and can be compared to AAI of Vitamin C and BHT (AAI are 11.320 and 7.850, respectively). The water and water-ethanol extracts of Microporus xanthopus showed a very strong activity (AAI values of 3.88 and 4.13, respectively).The ethanol extract of Microporus xanthopus and water, water-ethanol extracts of Polyporus fasciculatus showed a strong activity (AAI values of 1.40; 1.70 and 1.88, respectively).The ethanol extract of Polyporus fasciculatus showed a moderate activity (AAI values of 0.71 ). The moderate activity was found in water and water-ethanol extracts of Ganoderma orbiforme.

\section{Antiangiogenic Activity}

The antiangiogenic potential of the extracts was evaluated in vivo with the chicken chorioallantoic membrane (CAM) the eighth embryonic day. The fertilized eggs were treated with aqueous extracts $(0.25-0.5 \mathrm{mg} / \mathrm{mL})$. The degree of vessel formation on CAM was scored 1 day later. The vessel density is the percentage of blood supply to the analysis area. It is inversely proportional to the degree of inhibition; plus the value of the density, the lower the degree of inhibition of angiogenesis is strong. In the presence of phosphate buffered saline buffer (PBS) used as a control, the target area has a vascularization percentage of $100 \%$, corresponding to a normal vasculature (Figure 1).Image analysis revealed that the degree of blood vessel formation in the presence of the extract was decreased compared with the normal vasculature (in the absence of the extract), and the avascularised area has been increased in a manner dependent on the concentration of the extract (Figure 1 (a)).The activity of the aqueous extract of Ganoderma orbiforme was evaluated at a concentration of $5 \mathrm{mg} / \mathrm{mL}$. On the one hand, Figure 2 (b) shows that Ganoderma orbiforme prevented the formation of new vessels, and decreased the density and number of vessels in the grafted area with whattman paper soaked with extract.
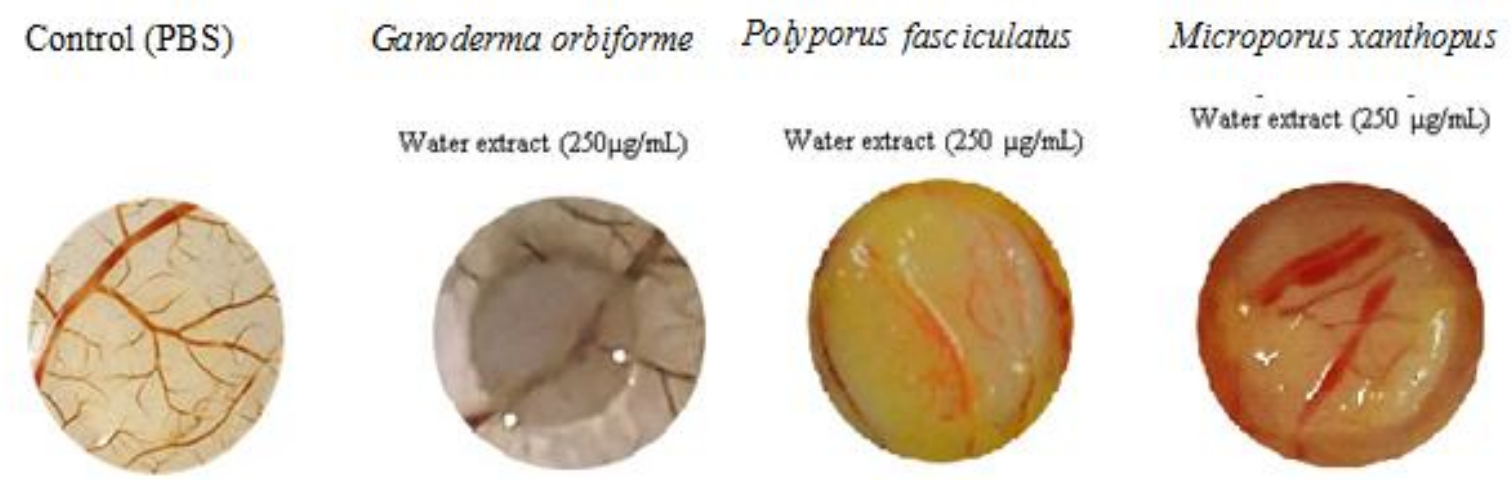

(a)

\section{Density (\%)}




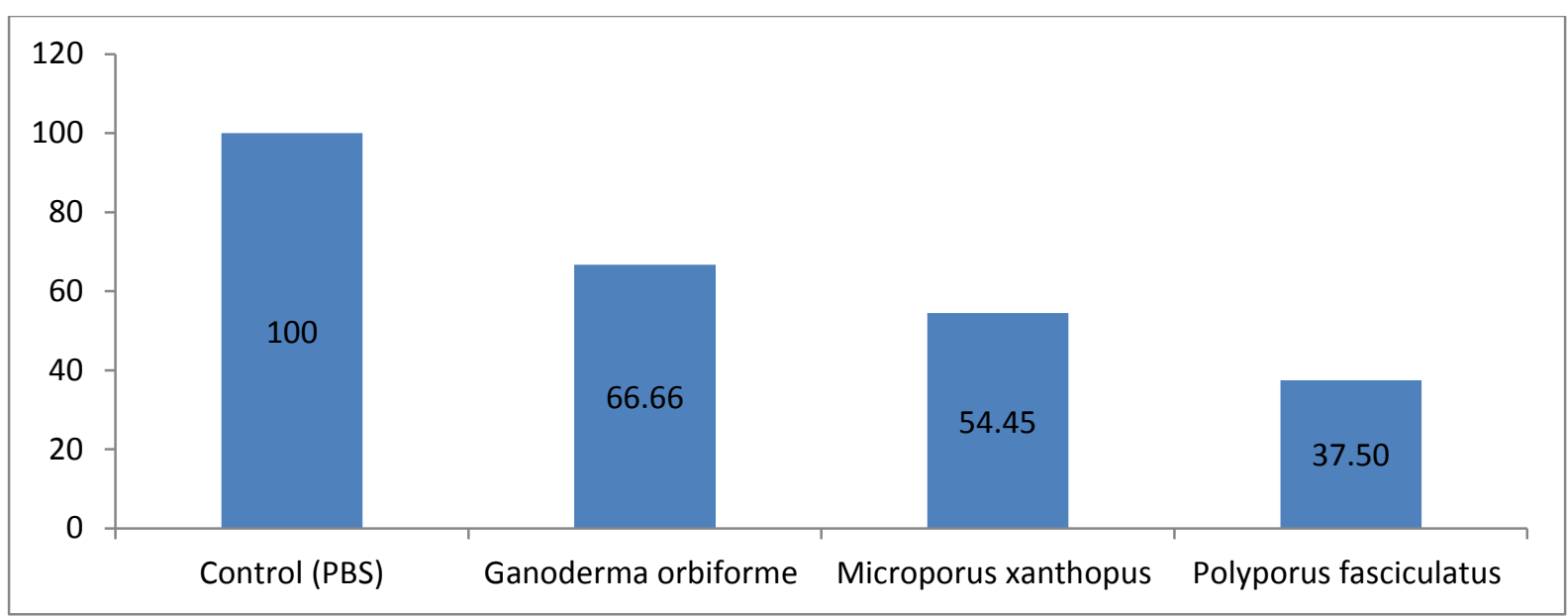

(b)

Figure 2: Inhibitory effects of water extracts of Microporus xanthopus, Ganoderma orbiforme and Polyporus fasciculatus on angiogenesis.

(a) The CAM of an 8 days old chick embryo was separately exposed to PBS (control). Extracts were introduced on top of the CAMs. After $24 \mathrm{~h}$ of incubation, the CAM tissue directly beneath each filter disk was resected, and digital images of the CAM sections were captured.

(b) The bar graph represents the number of branches after action of extracts. Photographs were imported into an image software program to visualize the new vessel branch points. Data are shown as the mean \pm SD: $p<0.05$ compared with untreated control. None of the tested concentrations $(0.25 \mathrm{mg} / \mathrm{mL})$ of the water extract display statistically significant differences with respect to each other.

Indeed, the CAM presented non-contiguous vessels that did not appear in the grafted area. On the other hand, the comparison with PBS shows that the number of vessels was reduced to 2 in the presence of Ganoderma orbiforme. That is a percentage inhibition of $66.67 \%$. The CAM treated with the aqueous extract of Polyporus fasciculatus at $250 \mu \mathrm{g} / \mathrm{mL}$ exhibited less dense and fewer vessels than those present in the CAM treated with PBS. Analysis of the vascularization of the CAM after treatment with Microporus xanthopus at $2 \mathrm{mg} / \mathrm{mL}$ showed a decrease in density and number of vessels with a percentage inhibition of 55.45\%. Polyporus fasciculatus induced a percentage inhibition of $37.50 \%$.The status of embryos after action on vascularization extracts information on toxicity (Table 4). 
Table 4: Antiangiogenic effect of Microporus xanthopus, Ganoderma orbiforme and Polyporus fasciculatus

\begin{tabular}{lllllll}
\hline & $\begin{array}{l}\text { Dose } \\
\boldsymbol{\mu g} / \mathbf{m L} \\
\mathbf{p e r} \text { eggs }\end{array}$ & $\begin{array}{l}\text { Tested } \\
\mathbf{e g g s} \\
(\mathbf{n})\end{array}$ & $\begin{array}{l}\text { Embryos } \\
\text { status } \\
\text { after 24h }\end{array}$ & $\begin{array}{l}\text { Antiangiogenic } \\
\text { effect }\end{array}$ & $\begin{array}{l}\text { Vessels } \\
\text { nombers }\end{array}$ & $\begin{array}{l}\text { Density } \\
(\%)\end{array}$ \\
\hline $\begin{array}{l}\text { PBS } \\
\text { (control) }\end{array}$ & & 6 & living & - & 24 & 100 \\
$\begin{array}{l}\text { Microporus } \\
\text { xanthopus }\end{array}$ & 250 & 6 & living & +++ & 24 & 55.45 \\
$\begin{array}{l}\text { Ganoderma } \\
\text { orbiforme }\end{array}$ & 250 & 6 & living & +++ & 24 & 66.66 \\
$\begin{array}{l}\text { Polyporus } \\
\text { fasciculatus }\end{array}$ & 250 & 6 & living & +++ & 24 & 37.50 \\
\hline
\end{tabular}

\section{DISCUSSION}

Microporus xanthopus, Ganoderma orbiforme and Polyporus fasciculatus, contain abundant coumarins, polyphenols, alkaloids and reducing sugars. The results of the determination of total phenolic, total flavonoids, total tannins and total proanthocyanidins show that the various extracts derived from these fungi are rich in polyphenol. Proanthocyanidins have been reported to exhibit many beneficial health effects such as antioxidant and anti-carcinogenic effects. Thus, Ba et al., in 2012 [21], have reported that taken together, the proanthocyanidins could be used as a potential natural cancer chemopreventive agent through Nrf2/ARE mediated phase II detoxifying/antioxidant enzymes induction via p38 and PI3K/Akt pathway. Phenolic substances have been suggested to play a preventive role in the development of chronic diseases such as cancer and heart disease.Several researchers have shown that polyphenols are highly active compounds against inflammatory diseases, cardiovascular, neuro-degenerative (Parkinson's and Alzheimer's disease), are powerful antioxidants and antivirals agents [22].

The crude extract of Microporus xanthopus, Ganoderma orbiforme and Polyporus fasciculatus show best DPPH free radical-scavenging activities. The results of Ganoderma orbiforme, however, differ from those obtained by Mbayo et al. in 2015 [23] in the evaluation of antioxidant activity with DPPH as a free radical, after an ascending thin layer chromatography. In this work, the various authors have shown that Ganoderma orbiforme possess a strong antioxidant activity. On the other hand, this result is surprising and unexpected because of its amount of phenolic compounds. The latter have beneficial biological effects to scavenge free radicals [24], important property underlying their various biological and pharmacological activities [25].A number of studies conducted on plant and fungal samples in order to evaluate their antioxidant efficacy have confirmed that organic extracts rich in total phenolic compounds exert potent antioxidant activities [26, 27, 28]. Phenolic extracts have been reported to retard lipid oxidation in oils and fatty foods [29], decrease the risk of heart diseases by inhibiting the 
oxidation of low-density lipoproteins. They are also known to possess antibacterial, antiviral, antiangiogenic and anticarcinogenic properties $[12,14,28,30]$.

The anti-angiogenic effect of water extracts of these fungi on the chicken embryo CAM revealed that these extracts had anti-angiogenic properties. No embryo death was recorded in the concentration range tested indicating that the observed anti-angiogenic activity is not due to the toxicity of the extracts.Inhibition was dose dependent. Studies by Song et $a l$. in2004 and Jang et al. in 2010 [31, 32] have shown that Ganoderma orbiforme extracts suppress angiogenesis in human cancer cells. These extracts have anti-angiogenic activity much greater than that of mannose 6-phosphate with a $38 \%$ densityat $60 \mathrm{mg} / \mathrm{mL}$ and of the reference molecules, sunitinib (Sutent ${ }^{\mathrm{TM}}$ ) [33]. Furthermore, a combination of four compounds called SMYGT (Sargassum fusiforme, Laminaria japonica, Ostreagiga sand Prunella vulgaris) at 0.4 $\mathrm{mg} / \mathrm{mL}$, has a $10 \%$ density, so an antiangiogenic activity less than what offer the water extract of Ganoderma orbiforme, Microporus xanthopus and Polyporus fasciculatus [19]. These aqueous extract showed strong antiangiogenic activity by not only,the inhibition of blood vessel formations on chick embryo chorioallantoic membrane (CAM), but also reducing and/or canceling of vessel's diameters. Inhibition was dose dependent. In the range of doses tested, no dead embryos were recorded, indicating that the antiangiogenic effect observed was not due to the toxicity of the plant. This extract shows a stronger anti-angiogenic activity than the aqueous extracts of Oncoba welwitschii and Tetrorchidium oppositifolium, which showed a percentage inhibition of $83.334 \%$ at $500 \mathrm{~g} / \mathrm{mL}$ [34]. Therefore, according to the results, the aqueous extract of Lophira procera may have good inhibitory activity on tumor growth by blocking angiogenesis [28]. The antiangiogenic activity of Scyphocephalium ochocoa $\left(\mathrm{IC}_{50}=\right.$ $1.153 \pm 0.089 \mu \mathrm{g} / \mathrm{mL})$ is lower than that of the reference drug, sorafenib $\left(\mathrm{IC}_{50}=0.197 \pm 0.062\right.$ $\mu \mathrm{g} / \mathrm{mL})[35]$.

\section{CONCLUSION}

The works of Folkman (1961) made it possible to elucidate the link between cancer and angiogenesis. Thus, it has emerged that anti-angiogenic therapy is a highly effective strategy that represents a treatment, not curative, but that supersedes conventional treatments used in cancer therapy. In addition, as antioxidant molecules protect cellular components from oxidative damage, the consumption of antioxidant-rich substances can help prevent cancer and other chronic diseases. As a result, this work consisted of testing the antioxidant and antiangiogenic potential of Microporus xanthopus, Polyporus fasciculatus and Ganoderma orbiforme from Gabon. The results of the phytochemical screening supported by the determination of the phenolic compounds of the water, water-ethanol and ethanol extracts of these fungi showed that all the fungi contained phenolic compounds and the phenolic 
compound contents of the extracts were proportional to the antioxidant activity. Although some had mild or moderate activities, other extracts had stronger activities. The anti-angiogenic activity of the aqueous extracts of these fungi on the chicken embryo CAM revealed that these extracts had anti-angiogenic potentialities. These fungi could thus be potential sources of myco-drugs.

\section{ACKNOWLEDGEMENTS}

The authors are very much thankful to Shell-Gabon for the financial support of materials in Laboratory of Research in Biochemistry of University of Sciences and Technology of Masuku, Franceville-Gabon (Grant No. SG/CIS/SDM/SA/ san 77).

\section{CONFLICT OF INTEREST}

The authors declare that there are no competing interests. All the authors read and approved the final version.

\section{REFERENCES}

1. WHO. Centre des médias Cancer. Aide-mémoire $\mathrm{N}^{\circ}$ 297. 2015.

2. Parkin DM, Bray F, Ferlay J and Jemal A. Cancer in Africa 2012. Cancer Epidemiol Biomarkers \& Prevention, 2014; 23(6), 953-966.

3. Ferlay J, Shin HR, Bray F, Forman D, Mathers C, Parkin DM. Estimates of worldwide burden of cancer in 2008: GLOBOCAN 2008. Int J Cancer. 2010; 15; 127(12): 2893917.

4. Bernard WS and Christopher PW. World cancer report 2014, IARC. Geneva, Switzerland: World health organization, International Agency for Research on Cancer, WHO press. 2015; ISBN 978-92-832-0429-9.

5. Folkman J. Tumor angiogenesis: therapeutic implications. New England J Med. 1971; 285: 1182-1186.

6. Chung A. S. and Ferrara N. Developmental and pathological angiogenesis. Annual Rev. Cell Develop Biol. 2011; 27: 563-584.

7. Sosa V, Molin'e T, Somoza R, Paciucci R, Kondoh HL, Leonart M. “Oxidative stress and cancer: an overview," Ageing Research Rev. 2013; 12 (1): 376-390.

8. Solomon P. Current findings, future trends, and unsolved problems in the studies of medecinal mushrooms. Biomed J. 2011; 89 (5):1323-1332.

9. EyiNdong HC, Degreef J, De Kessel A. Champignons comestibles des forêts denses d'Afrique centrale Taxonomie et Identification. Abc Taxa. 2011; 10: 262.

10. Ciulei I. (1964): Practical manuals on the industrial utilization of medicinal and aromatic plants. University of Bucharest, Romania. 
11. Vernon LS, Orthofer R, Lamuela-Raventos RM. Analysis of total phenols and other oxidation substrates and antioxidants by means of Folin-Ciocalteu reagent. Methods Enzymol. 1999; 299: 152-178.

12. Sima OC, Ondo JP, Ndong AGR, Obame ELC, Djoba SJF, Nsi EE. Phytochemical screening, antioxidant and antimicrobial potential of stem barks of Coula edulis Baill. Pseudospondias longifolia Engl. and Carapa klaineana Pierre.from Gabon. Asian Pac J Trop Disease. 2016; 6 (7): 557-563.

13. Quettier-Deleu C, Gressier B, Vasseur J, Dine T and Brunet C. Phenolic compounds and antioxidant activities of buckwheat (Fagopyrum esculentum Moench) hulls and flour. J Ethnopharmacol. 2000; 72: 35-42.

14. Obame-Engonga LC, Abdoul-Latif-Fatouma M, Ondo JP, Sima-Obiang C, NgouaMeye-Misso RL, Traoré A and Koudou J. Phytochemical screening, antioxidant and antibacterial activities of Guibourtia ehie and Syzygium rowlandii medicinal plants from Gabon. Int J Current Research. 2017; 9 (08): 56354-56360.

15. The reference method of European community was used to measure total amount of tannins (1994).

16. Prigent S. Interactions of phenolics compounds with globular proteins and their effects on food related functional properties. $\mathrm{PhD}$ Thesis, Wageningen University, Wageningen, Netherlands.2005; 131-133.

17. Scherer R and Godoy HT. Antioxidant activity index (AAI) by 2,2-diphenyl-1picrylhydrazyl method. Food Chem. 2009; 112 (3): 654-658.

18. Lee JS, Shukla S, Kim JA, Kim M. Anti-angiogenic effect of Nelumbo nucifera leaf extracts in human umbilical vein endothelial cells with antioxidant potential. PLoS One. 2015; 10 (2): 1-17.

19. Yi JM, Bang OS, Kim NS.An evaluation of the anti-angiogenic effect of the Korean medicinal formula "Sa-mi-yeon-geon-tang in vitro and in ovo. BMC Compl Alter Med. 2015; 15 (42): 1-9.

20. Abdoul-latif FM, Bayili RG, Obame ELC, Bassolé IHN, Dicko MH. Comparison of phenolic compounds and antioxidant capacities of traditional sorghum beers with other alcoholic beverages. Afr J Biotech. 2012; 11 (81): 14671-14678.

21. Ba K, Tine E, Destain J, Cissé N, Thonart P. Étude comparative des composés phénoliques, du pouvoir antioxydant de différentes variétés de sorgho sénégalais et des enzymes amylolytiques de leur malt. Biotech. Agron., Soc. Environment. 2010; 14 (1): 131-139. 
22. Njintang YN, Tatsadjieu-Ngoune L, Ngakou A, Danra D and Tchuenguem-Fohouo FN. Antiradical activity and polyphenol content of ethanolic extracts of Propolis. Int $\mathbf{J}$ Biosci. 2012; 2 (4): 56-63.

23. Mbayo MK, Kalonda EM, Tshisand PT, Tatchoua O. Criblage chimique de quelques champignons du Katanga (RDC) et évaluation de leur activité biologique. Int J Innov Applied Studies. 2015; 10 (1): 435-449.

24. Razali N, Razab R, Junit SM, Aziz AA. Radical scavenging and reducing properties of extracts of cashew shoots (Anacardium occidentale). Food Chem. 2008; 111 (1): 3844.

25. Ondo JP, Obame ELC, Andzi BT, Nsi AG, Nsi EE and Lebibi J. Phytochemical screening, total phenolic content and antiradical activity of Asplenium africanum (Aspleniaceae) and fruit of Megaphrinium macrostachyum (Marantaceae). J Applied Pharmaceu Sci. 2013; 3 (08): 092-096.

26. Jeyapragash D, Subhashini P, Raja S, Abirami K, Thangaradjou T. Evaluation of Invitro antioxidant activity of Seagrasses: Signals for potential alternate source. Free Radicals and Antioxidants. 2016; 6 (1): 77-89.

27. Sima-Obiang C, Ngoua-Meye-Misso RL, Ndong-Atome GR, Ondo JP, ObameEngonga LC, Nsi-Emvo E. Chemical composition, antioxidant and antimicrobial activities of stem barks of Englerina gabonensis Engler and Sterculia tragacantha Lindl from Gabon. Int J Phytomed. 2017; 9 (3): 501-510.

28. Ngoua MMRL, Sima OC, Ndong JC, Ondo JP, Ovono AF, Obame ELC. Phytochemical screening, antioxidant, anti-inflammatory and antiangiogenic activities of Lophira procera A. Chev. (Ochnaceae) medicinal plant from Gabon. Egypt J Basic Applied Sci. 2018; 5 (2018): 80-86.

29. Marwa EEDI and Hany GEM. Phenolic content and antioxidant activity of Cantaloupe (Cucumismelovar. cantalupensis) and food application. Int J Nutr Food Sciences. 2016; 5(1): 16-24.

30. Rebensburg S, Helfer M, Schneider M, Koppensteiner H, Eberle J, Schindler M, Gürtler L, Brack-Werner R. Potent in vitro antiviral activity of Cistus incanus extract against HIV and Filoviruses targets viral envelope proteins. Scientific Reports. 2016; 6 (20394): 1-15.

31. Song YS, Sun-Hyoung K, Jae-Hoon S, Changbae J, Chang-Jin L, Eun-Hee P. Antiangiogenic and inhibitory activity on inducible nitric oxide production of the mushroom Ganoderma lucidum. J Ethnopharmacol. 2004; 90, 17-20. 
32. Jang KJ, Han MH, Lee BH, Kim BW, Kim CH, Yoon HM, Choi YH. Induction of apoptosis by ethanol extracts of Ganoderma lucidum in human gastric carcinoma cells. J Acupunct Meridian Stud.2010; 3: 24-31.

33. Combemale S, Assam-Evoung JN, Houaidji S, Bibi R, Barragan-Montero V. Gold nanoparticles decorated with mannose-6-phosphate analogue. Molecules. 2014; 19(1): 1120-1149.

34. Ngoua MMRL, Ondo JP, Assam EJN, Orango BJO, Sima OC, Ndong JC, Ovono AF, Obame ELC. Phytochemical screening, antioxidant and antiangiogenic properties of Oncoba welwitschii (Oliv.) Gilgn. And Tetrorchidium oppositifolium (Pax. and Khoffm.), medicinal plants from Gabon. IJIRSET. 2017; 6(1): 1-10.

35. Ngoua MMRL, Ndong JDLC, Sima OC, Ondo JP, NdongAGR, Ovono AF, Obame ELC.Phytochemical studies, antiangiogenic, anti-inflammatory and antioxidant activities of Scyphocephalium ochocoa Warb. (Myristicaceae), medicinal plant from Gabon. Clinical Phytoscience, 2018; 4:15.

AJPHR is

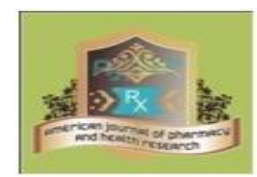

Peer-reviewed

monthly

Rapid publication

Submit your next manuscript at

editor@ajphr.com / editor.ajphr@gmail.com 